\title{
Dissolved gas analysis (DGA) of vegetable oils under electrical stress
}

\begin{abstract}
Dissolved gas analysis (DGA) is often use by the utility companies to monitor the health and to detect any faults of their transformers. The concentration and proportion of various gases dissolved in the oil are used to indicate whether there is an electrical or thermal fault within the transformer. A lot of data have been published in the literature on DGA levels for a mineral oil. However, the data for vegetable oils are relatively sparse even though the vegetables oils have been used for more than 10 years in distribution transformers. In this paper, the concentration of dissolved gasses under electrical performance in rice bran oil (RBO) and palm oil (PO) were investigated. These two oils were selected since they show promising potential as alternative insulating dielectric liquid for transformer and easily obtained in Malaysia. Three different gaps $(2.5 \mathrm{~mm}, 5 \mathrm{~mm}$ and $10 \mathrm{~mm})$ with sphere to sphere configuration were used in this study. The samples were filtered for three times and dried at $85^{\circ} \mathrm{C}$ for 48 hours before testing. The AC breakdown experiments were performed in the high voltage laboratory for 100 times. The dissolved gasses from the electrical breakdown voltages were obtained in 2 liter sealed test cell. The gasses concentrations were measured using Gas Chromatography equipment. There were six concentrations of gases contained in the samples which are Hydrogen $(\mathrm{H} 2)$, Methane $(\mathrm{CH} 4)$, Ethane $(\mathrm{C} 2 \mathrm{H} 6)$, Ethylene $(\mathrm{C} 2 \mathrm{H} 4)$, Acetylene $(\mathrm{C} 2 \mathrm{H} 2)$ and Carbon monoxide $(\mathrm{CO})$. These gasses were interpreted using IEC ratio, Roger ratio, Dornenburg ratio method and Duval Triangle method in order to investigate whether the existing techniques are suitable for RBO and PO. From the experiments, $\mathrm{C} 2 \mathrm{H} 2$ and $\mathrm{H} 2$ were the highest amount of gases detected for all samples. The Duval triangle method is the best method in detecting the fault for these oils under electrical breakdown. However, the ratio methods have some limitation in predicting the faults.
\end{abstract}

Keyword: Vegetable oils; AC breakdown voltage; DGA; Interpretation methods 